\title{
Recombinant tandem multi-linear neutralizing epitopes of human enterovirus 71 elicited protective immunity in mice
}

Yue-Xiang $\mathrm{Li}^{1,2 \dagger}$, Hui Zhao ${ }^{2 \dagger}$, Rui-Yuan $\mathrm{Cao}^{2}$, Yong-Qiang Deng ${ }^{2}$, Jian-Feng Han ${ }^{2}$, Shun-Ya Zhu ${ }^{2}$, Jie Ma ${ }^{2}$, Long Liu ${ }^{1,2}$, E-De Qin ${ }^{1,2}$ and Cheng-Feng Qin ${ }^{1,2^{*}}$

\begin{abstract}
Background: Human Enterovirus 71 (EV71) has emerged as the leading cause of viral encephalitis in children, especially in the Asia-Pacific regions. EV71 vaccine development is of high priority at present, and neutralization antibodies have been documented to play critical roles during in vitro and in vivo protection against EV71 infection.

Results: In this study, a novel strategy to produce EV71 vaccine candidate based on recombinant multiple tandem linear neutralizing epitopes (mTLNE) was proposed. The three well identified EV71 linear neutralizing epitopes in capsid proteins, VP1-SP55, VP1-SP70 and VP2-SP28, were sequentially linked by a Gly-Ser linker $\left(\left(\mathrm{G}_{4} \mathrm{~S}\right)_{3}\right)$, and expressed in E.coli in fusion with the Trx and His tag at either terminal. The recombinant protein mTLNE was soluble and could be purified by standard affinity chromatography. Following three dosage of immunization in adult mice, EV71-specific IgG and neutralization antibodies were readily induced by recombinant mTLNE. IgG subtyping demonstrated that lgG1 antibodies dominated the mTLNE-induced humoral immune response. Especially, cytokine profiling in spleen cells from the mTLNE-immunized mice revealed high production of IL-4 and IL-6. Finally, in vivo challenge experiments showed that passive transfer with anti-mTLNE sera conferred full protection against lethal EV71 challenge in neonatal mice.
\end{abstract}

Conclusion: Our results demonstrated that this rational designed recombinant mTLNE might have the potential to be further developed as an EV71 vaccine in the future.

Keywords: Enterovirus 71, Vaccine, Linear neutralizing epitopes

\section{Introduction}

Human enterovirus 71 (EV71), a typical single-stranded, positive-sense RNA virus, belongs to the Enterovirus genus of the Picornaviridae family. In recent years, EV71 has emerged as the most important causative agent of Hand, Foot and Mouse disease (HFMD) affecting mostly young children, especially those younger than 5 years old. The clinical symptoms of EV71 infection include simple exanthema, serious aseptic meningitis, acute flaccid paralysis as well as brainstem encephalitis [1]. Although present in most countries, the largest outbreaks of disease have been seen in the Asia-Pacific region over the past 15 years [2-6],

\footnotetext{
* Correspondence: qincf@bmi.ac.cn

†Equal contributors

'Graduate School, Anhui Medical University, Hefei 230032, Anhui, China 2Department of Virology, State Key Laboratory of Pathogen and Biosecurity, Beijing Institute of Microbiology and Epidemiology, Beijing, China
}

and many areas have experienced cyclical epidemics that occur every 2-3 years [7-10]. EV71 infection has now been recognized as an important global public health issue.

Vaccination probably offers the best option for disease control, but there is no available licensed vaccine against EV71. Several vaccine candidates including formaldehydeinactivated whole-virus vaccine, live-attenuated vaccine, virus-like particles (VLPs), DNA vaccine and subunit vaccine, have showed promise for clinical use [11-20]. Especially, inactivated EV71 vaccines manufactured in mainland China have undergone phase III clinical trials with ideal efficacy [21].

The genome of EV71 is about $7.4 \mathrm{~kb}$ in length, which first encodes a long polyprotein with a single open reading frame followed by a poly A tract. Then, the polyprotein is divided into three different precursor proteins (P1, P2 and 
P3). The P1 precursor protein is further cleaved to four structural proteins, including VP0 (the precursor of VP2 and VP4), VP3 and VP1, which make up the capsid; whereas P2 and P3 are cleaved to non-structural proteins that are involved in genome replication and translation [22]. Among the capsid protein, VP1, VP2, and VP3 are external, and well exposed to host immune system. Neutralizing antibodies against EV71 have been demonstrated as the most important factors in limiting the severity of infection [23]. Several linear neutralizing epitopes have been identified within the capsid proteins of EV71. Foo and colleagues have characterized two neutralizing epitopes in VP1, SP55 (amino acids 163-177) and SP70 (amino acids 208-222), both were capable of eliciting neutralizing antibodies and conferred protection against homologous and heterologous EV71 strains in neonatal BALB/c mice [24]. Moreover, monoclonal antibody targeting the linear epitope on VP1 protein, spanning amino acids 215-219, provided full protection against EV71 challenge in vivo [25,26]. Recently, screening with overlapping synthetic peptides covering the entire capsid protein of EV71 identified SP28 (amino acids 136-150 of VP2) as potential neutralizing epitope [27]. Epitope-based vaccines containing well-defined protective epitopes are supposed to stimulate effective and specific protective immune responses while avoiding potential undesirable side-effect $[28,29]$. Various epitope-based vaccine candidates against virus infection have been well demonstrated with ideal immunogenicity and protection [30-32], and several promising pre-clinical and clinical trials for vaccines that involve peptide-based strategies are currently being carried out [33,34], yet only a few epitopebased EV71 vaccines have been described $[24,35,36]$.

In this study, a novel EV71 epitope-based vaccine candidate was designed through tandem connecting the three known EV71 neutralizing epitopes with the Gly-Ser linker and expressed in E.coli. This recombinant multiple tandem linear neutralizing epitopes, named mTLNE, was evidenced to evoke humoral and cellular immune responses and passive transfer with anti-mTLNE sera conferred full protection against lethal EV71 challenge in mice.

\section{Results}

\section{Expression and characterization of recombinant mTLNE}

The three known EV71 linear neutralizing epitopes (VP1-SP55, VP1-SP70 and VP2-SP28) were sequentially connected by a linker $\left(\left(\mathrm{Gly}_{4} \mathrm{Ser}\right)_{3}\right)$ and inverted into the expression plasmid pET32a (Figure 1A). Trx was fused at the N-terminal to enhance solubility and immunogenicity, and the C-terminal His-Patch was included for purification on metal-chelating resin. As shown in Figure 1B, the expressed mTLNE was approximately $30 \mathrm{kDa}$ (lane 1 and 2), and the control Trx was about $20.8 \mathrm{kDa}$ (lane 4 and 5) as expected. The majority of recombinant proteins retained in supernatant after sonication (lane 2), indicating that
mTLNE was mainly in the form of solubility in E.coli. After a single purification with Ni-NTA agarose, recombinant mTLNE was isolated as a single band (lane 3). Thus, soluble mTLNE was highly expressed in E.coli and easily purified by standard affinity chromatography.

Western blotting assay was performed to characterize the antigenicity of mTLNE. The result showed that mTLNE could be recognized by mouse anti-EV71 polyclonal antibody (Figure 2A). Further analysis with ELISA confirmed that recombinant mTLNE could specifically react with mouse and rabbit antisera against EV71 (Figure 2B), meanwhile the control protein Trx had only an insignificant background reading. These data suggested that recombinant protein mTLNE possessed good immune reactivity, and was potential to be an EV71 antigen as originally designed.

\section{Recombinant mTLNE induced EV71-specific humoral and cellular immune response in mice}

To test the immunogenicity of recombinant mTLNE in mice, groups of BALB/c mice were immunized with mTLNE three times at two-week intervals. Group of mice immunized with equal dose of Trx protein was set as control. Serum samples were collected at two weeks after each immunization and EV71-specific antibody response were determined accordingly. Firstly, the immuno-reactivity of the anti-mTLNE sera was determined by Western blotting using EV71 virions (Figure 3A). The results showed that the anti-mTLNE sera were reactive with three EV71 capsid proteins, including VP0 (35 kDa), VP1 $(32 \mathrm{kDa})$ and VP2 $(28 \mathrm{kDa})$. The results confirmed that immunization with mTLNE was capable of inducing antisera recognizing VP1 and VP2 proteins of EV71.

Then, EV71-specific IgG antibody response was measured by indirect immunofluorescence assay (IFA). The results showed that IgG antibodies were readily induced in each mTLNE-immunized mice at two weeks post prime immunization, and the IgG titers gradually increased along with boost immunizations. After the third immunization, the $\lg$ titer peaked at 1:3191, and no detectable IgG antibody was observed in mice immunized with Trx as expected (Figure 3B). Subsequently, ELISA was performed to characterize the antibody reactivity to each individual EV71 epitope. The results revealed that higher titers of IgG antibody against the three epitopes (VP1-SP55, VP1-SP70 and VP2-SP28) were induced in the mTLNE-immunized mice (Table 1). IgG subtyping results showed that the level of IgG1 in mTLNE-immunized mice was significantly higher than that of control group, while no significant difference was observed for IgG2a, IgG2b and IgG3 (Figure 4). Furthermore, neutralizing antibodies assay showed that three doses of mTLNE immunization elicited high titer neutralizing antibodies against both genotype C4 (Figure 3C) and A strains of 


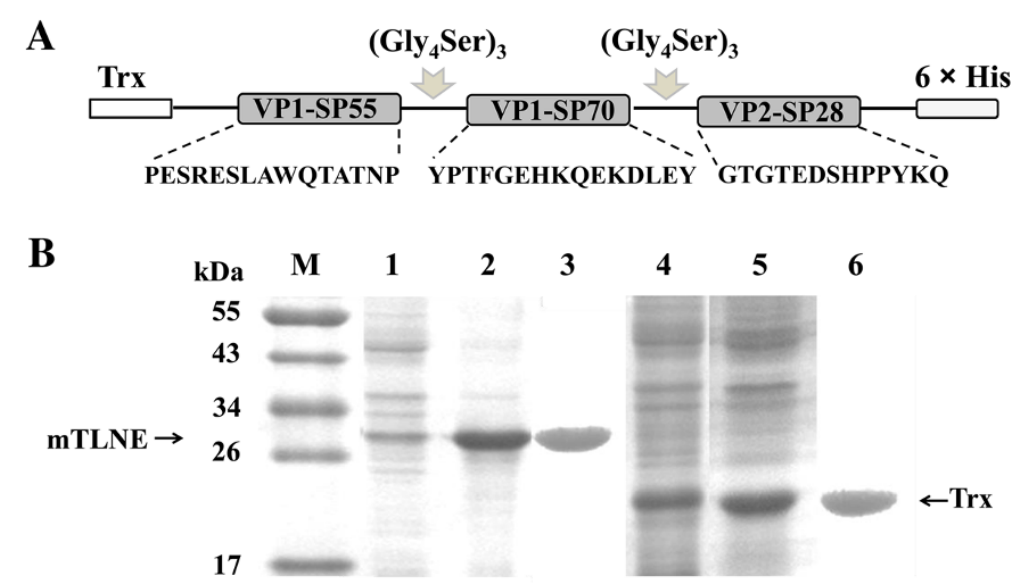

Figure 1 Expression and purification of recombinant mTLNE. (A) Schematic representation of the mTLNE constructs. Three linear neutralizing epitopes (VP1-SP55, VP1-SP70 and VP2-SP28) was sequentially linked with (Gly ${ }_{4}$ Ser) $)_{3}$ sequence. Thioredoxin (Trx) was fused at the N-terminal, and His-Patch at the C-terminal. (B) SDS-PAGE results of recombinant proteins. The induced cells were harvested by centrifugation, and the pellet was re-suspended completely by mixing in PBS. Following sonication, the supernatant and the precipitate were harvested and assessed on by SDS-PAGE. Prominent protein bands of about $30 \mathrm{kDa}$ and $20.8 \mathrm{kDa}$ were visible in induced fractions. Lanes 1 and 2: the precipitate and supernatant from E. coli receiving $\mathrm{pET} 32 \mathrm{a}-\mathrm{mTLNE}$. Lanes 4 and 5: the precipitate and supernatant from E. coli receiving pET32a plasmid. Lanes 3 and 6 : the purified recombinant mTLNE and Trx protein.

EV71 (Figure 3D), while no EV71-specific neutralizing antibodies were detected in all mice immunized with Trx.

To make sure whether cellular immunity was induced by mTLNE, splenocyte proliferative responses in mice immunized with mTLNE were determined by measuring the levels of IFN- $\gamma$, IL-2, IL-4 and IL-6. ELISPOT assay showed that high level of IL-4 and IL- 6 were predominantly produced in mTLNE-immunized mice in comparison to the control group. Meanwhile, no significant difference was observed in IL- 2 and IFN- $\gamma$ production between mTLNE-immunized and Trx-immunized mice (Figure 5). Taken together, these results demonstrated immunization with recombinant mTLNE were capabale of inducing EV71-specific humoral and cellular immune response in mice.

\section{Passive transfer with anti-mTLNE confers full protection} against lethal EV71 challenge in neonatal mice

Finally, the in vivo protective efficacy against lethal EV71 challenge was evaluated in an established neonatal mice model [37]. Mice were i.c. inoculated with lethal dose of EV71 and then i.p. administered with anti-mTLNE sera. Mice treated with PBS and anti-Trx sera were set as controls. As shown in Figure 6, all the mice treated with anti-mTLNE sera survived after the challenge, and none of them developed any clinical manifestations; meanwhile all mice that received anti-Trx sera or PBS became hairless lesions and paralysis of limbs at 5 days post-infection and all died within 10 days. Log-rank analysis showed that anti-mTLNE sera significantly prolonged the survival time and prevented EV71-caused mortality in mice in
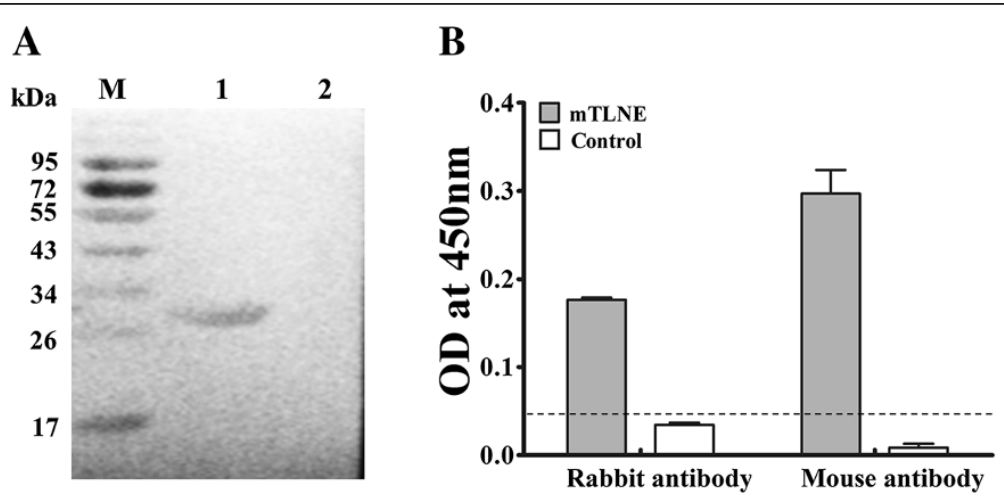

Figure 2 Serological characterization of recombinant mTLNE. (A) Western blotting assay using mouse polyclonal antibody against EV71. Lanes 1: mTLNE proteins; Lanes 2: Trx proteins. (B) ELISA using rabbit and mouse polyclonal antibodies against EV71. Recombinant mTLNE could be specifically recognized by the corresponding mouse and rabbit antibodies compared with the control Trx. The cut-off value for the ELISA is shown by a dotted line. 

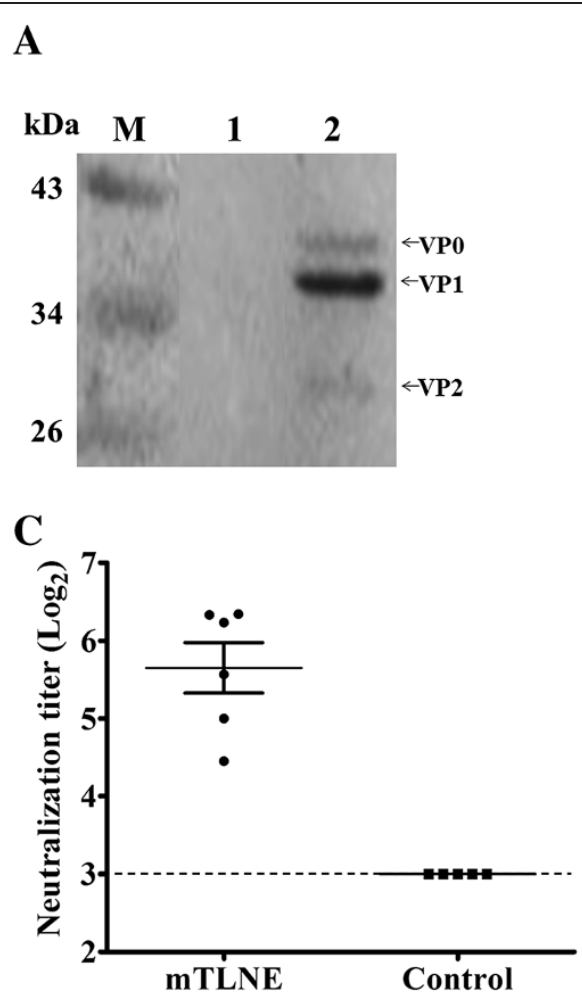

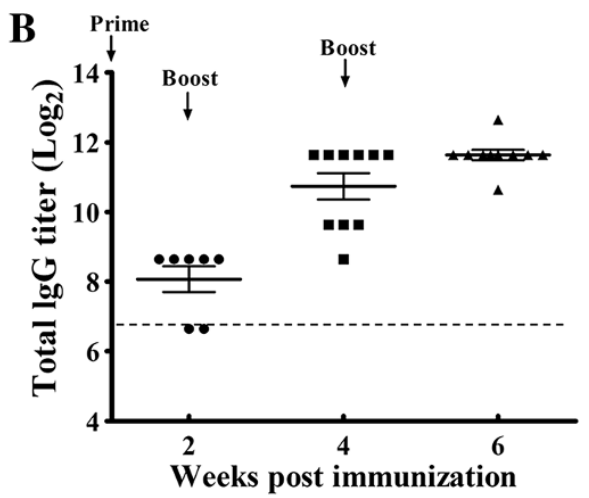

D

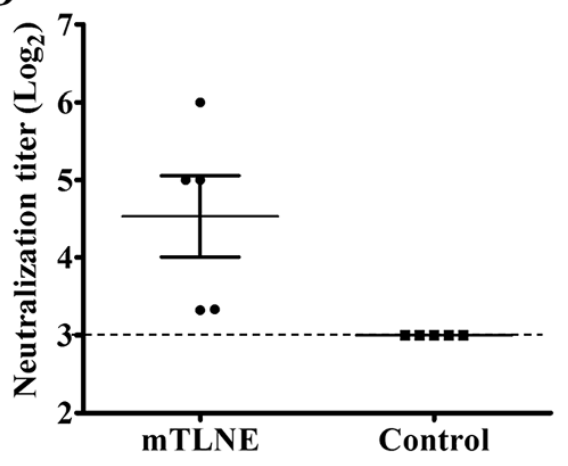

Figure 3 Humoral immune response in mice immunized with mTLNE. (A) The immunoreactivity of serum from mice immunized with mTLNE was determined by Western blotting. The total proteins of EV71 were harvested from infected cell lysate, and the cell lysate from the uninfected RD cells was used as control. Lanes 1: uninfected RD cell lysate. Lanes 2: the total proteins of EV71. The position of the three capsid proteins of EV71 (VPO, VP1 and VP2) was indicated by arrow, respectively. (B) The lgG antibody titer against EV71 was measured by IFA at two weeks after each immunization. (C and D) Neutralization antibody titer against EV71 strain AH08/06 (genotype (4) and prototype strain BrCr (genotype A) were measured by microneutralization assay at two weeks after the final immunization. Dotted lines represent limits of detection.

comparison with the controls. Together, these results demonstrated passive transfer with anti-mTLNE sera provided full protection against EV71 challenge in neonatal mice.

\section{Discussion}

Epitope-based vaccine provides an opportunity to rationally engineer specific epitopes to increase potency and breadth and avoid the potential side-effect of other unrelated epitopes that contribute few to protection [38,39]. To data, only a few epitope-based vaccines against EV71 have been described. In our study, we propose a novel strategy to connect the three identified linear neutralizing peptides

Table 1 ELISA titers against individual EV71 epitope

\begin{tabular}{lccc}
\hline & \multicolumn{3}{c}{ Synthetic peptides } \\
\cline { 2 - 4 } & VP1-SP55 & VP1-SP70 & VP2-SP28 \\
\hline mTLNE & $1: 246$ & $1: 1488$ & $1: 1710$ \\
Control & $<1: 100$ & $<1: 100$ & $<1: 100$ \\
\hline
\end{tabular}

Epitope specific lgG antibody titers of sera in two weeks after the last boost were assayed by ELISA, using corresponding unconjugated synthetic peptide as the capture antigen. Data represents the geometric mean titer of individual serum sample $(n=10)$ harvested from the immunized mice.

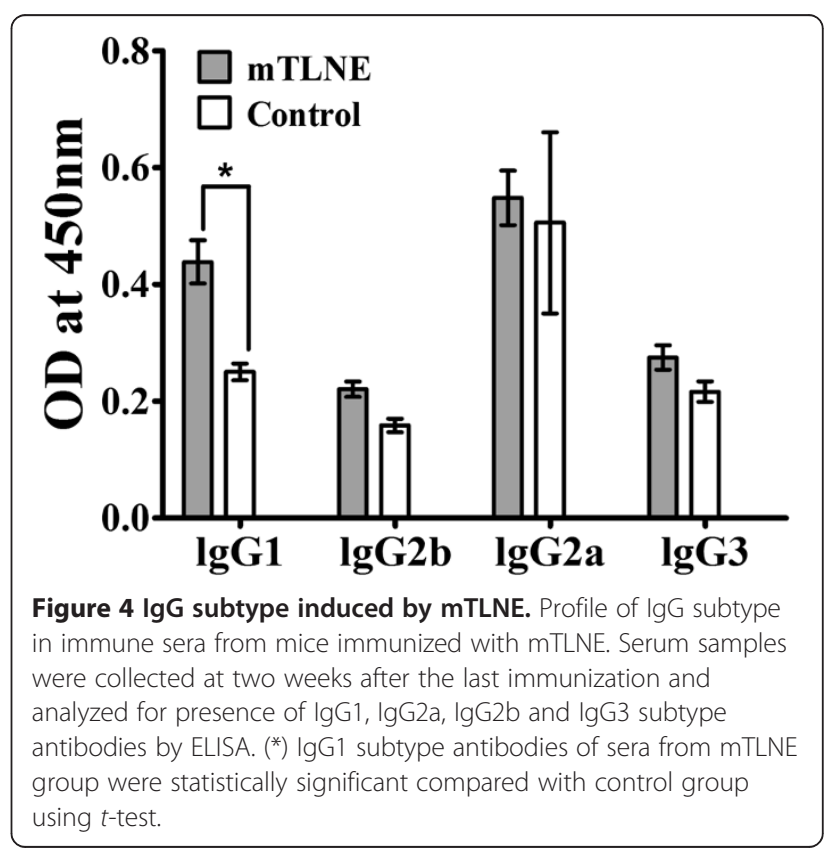




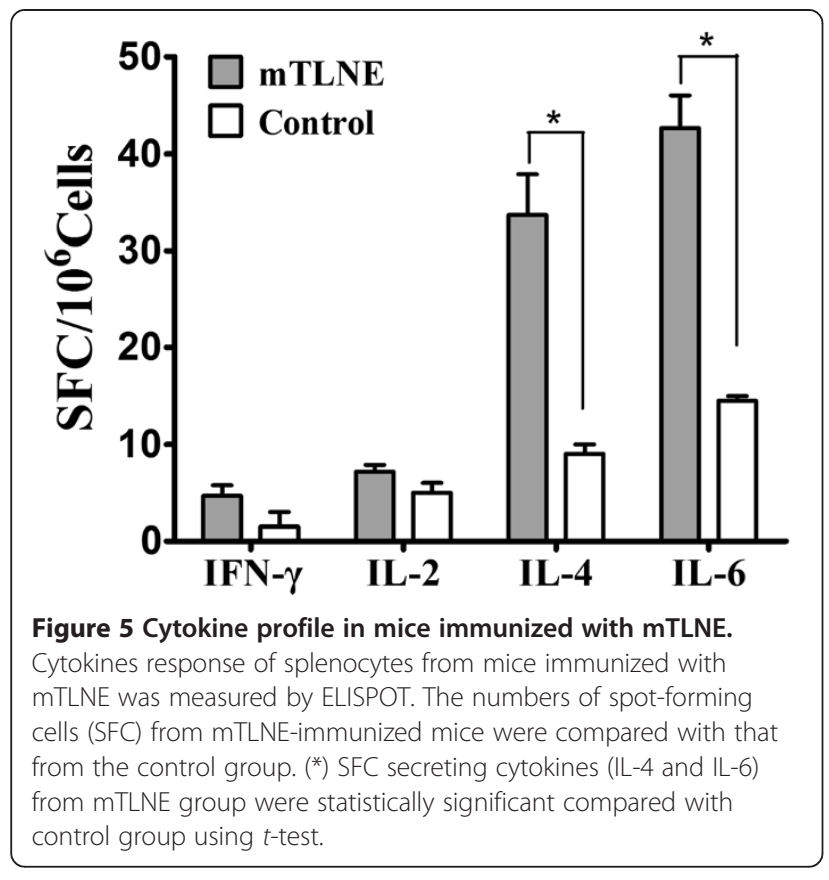

by a Gly-Ser linker, generating the recombinant epitopebased vaccine candidate mTLNE. Recombinant mTLNE was efficiently expressed in E. coli system and easily purified with affinity chromatography. The Gly-Ser linker was chosen to increase the flexibility of the recombinant protein, to minimize interference between adjacent epitopes, and to facilitate forming natural conformation [40]. The designed mTLNE contained two epitopes in VP1 and one epitope in VP2, and antisera from mice immunized

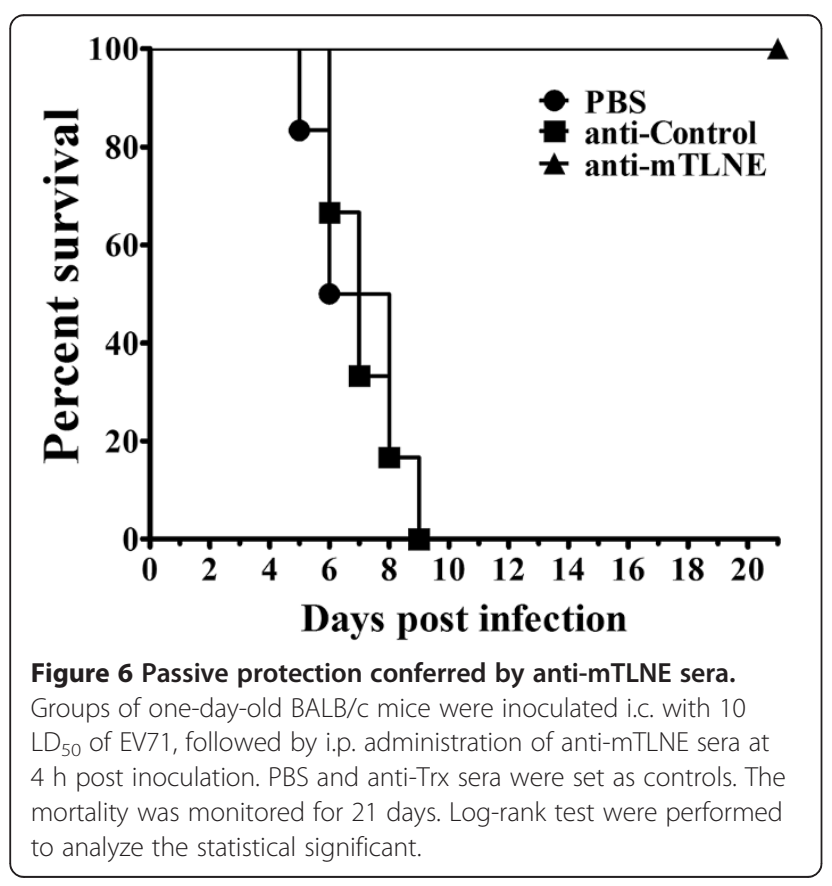

with mTLNE interacted simultaneously with both VP1 and VP2 proteins of EV71 (Figure 3A).

Further, immunization with mTLNE induced potent humoral immune responses as demonstrated by the elicitation of EV71-specific IgG antibodies (Figure 3B). Antibodies induced by mTLNE immunization were able to neutralize both the circulating strain AH08/06 and the prototype strain $\mathrm{BrCr}$ (Figure 3D), suggested that mTLNE might induce broad neutralization against homologous and heterologous genotypes of EV71. This is consistent with previous reports by Li et al. [41]. The specific IgG antibody response in mice appeared somewhat divergent among different epitopes, with relative low titer against VP1-SP55 (Table 1). Such immunogenic inferiority of SP55 epitope has also been observed by others [42]. These differences are likely a reflection of the nature of viral antigen.

In general, neutralizing antibodies are important index for protection against EV71 infection. In the present study, the geometric mean of neutralizing antibody titers induced by MTLNE was 50 , which was higher than that of single synthetic peptide-SP70 [24]. Compared with inactivated vaccines, the neutralizing titers elicited by mTLNE were relatively low due to lack of other antigens $[17,37]$. However, the advantage of this epitope based vaccine approach should not be highlighted. Especially, antibody-dependent enhancement (ADE) of EV71 infection has been observed in both experimental and clinical setting [41,43-45]. Recent findings from human intravenous immunoglobulin clarified the distinct function of each IgG subtype on neutralization and enhancement of EV71 infection [46], and IgG1 subtype is deemed to dominate neutralization while IgG3 associates with ADE. The robustness of IgG1 response, not IgG3, induced by mTLNE (Figure 4) indicated potential benefits for protection. Most importantly, our data clearly demonstrated that passive transfer of anti-mTLNE sera conferred full protection to neonatal mice against lethal EV71 challenge (Figure 6).

In addition to humoral immunity, mTLNE immunization induced cellular immune responses as evidenced by elevated production of specific cytokines (Figure 5). The production of IL-4 and IL- 6 in mTLNE-immunized mouse splenocytes suggested a Th2 immune response. In mice, IL- 4 and IL- 6 generally switches activated B cells to the IgG1 subtype, which was confirmed by IgG subtypes assay and IgG1 subtype was prevalent in case of mTLNE group (Figure 4). These observations suggest that mTLNE contain mainly B-cell epitopes, which has also been observed by Foo et al. [24,36]. Currently, only a few T-cell epitopes on the capsid proteins of EV71 have been identified $[47,48]$. In the future work, a peptide-based vaccine containing multiple B-cell epitopes as well as T-cell epitopes can be expected, which might be an ideal vaccine that are capability of inducing a protective 
antibody response and a cytotoxic $\mathrm{T}$-cell response important for killing infected host cells.

Overall, we propose a novel epitope-based vaccine approach by connecting linear neutralizing peptides, and primary immunogenicity and protection experiments in mice demonstrated the potential for further development as EV71 vaccine.

\section{Materials and methods}

\section{Cell lines and viruses}

Human Rhabdomyosarcoma RD cells and African green monkey kidney Vero cells were cultured in DMEM medium (Invitrogen) containing 10\% fetal bovine serum (FBS) (Hyclone) at $37^{\circ} \mathrm{C}$ in the presence of $5 \% \mathrm{CO}_{2}[46,49]$. EV71 prototype strain $\mathrm{BrCr}$ (GenBank accession no. U22521), belongs to genotype A, and genotype C4 strain AH08/06 (GenBank accession no. HQ611148.1) was isolated from an HFMD patient during an outbreak in 2008 in Anhui, China [50]. The EV71 virus stocks were propagated in RD cells according standard protocol and titers were determined in Vero cells [35,51].

\section{Preparation of mouse and rabbit polyclonal antibody against EV71}

The mouse polyclonal antibody against EV71 was prepared in our lab [41] and the rabbit polyclonal antibody against EV71 were prepared as followed. A rabbit (2.5$3 \mathrm{~kg}$ ) was immunized subcutaneouly (s.c.) with heatinactivated EV71 $\left(2 \times 10^{7} \mathrm{PFU} / \mathrm{ml}\right)$ employing Freund's complete adjuvant (Sigma), and boosted with the same dose antigen with Freund's incomplete adjuvant (Sigma). Two weeks after the boost immunization, serum samples were titrated and stored frozen until use.

\section{Overlap PCR amplification and plasmid construction}

The cDNA fragments encoding three tandem EV71 neutralizing epitopes (VP1-SP55, VP1-SP70 and VP2-SP28) which connected by the Gly-Ser linker $\left(\left(\mathrm{Gly}_{4} \mathrm{Ser}\right)_{3}\right)$ were amplified by overlap PCR. The primers and reaction conditions are available upon request. The PCR products were purified and inserted into the pET32a vector (Novagene) to generate the recombinant plasmid pET32a-mTLNE. The recombinant plasmid was confirmed by restriction enzyme digestion and DNA sequencing.

\section{Protein expression and purification}

The plasmid pET32a and pET32a-mTLNE was transformed in BL21 Chemically Competent cells (TIANGEN). The transformed BL21 cells were incubated with shaking at $37^{\circ} \mathrm{C}$ until $\mathrm{OD}_{600}$ reaches 0.6 , then induced with $0.1 \mathrm{mM}$ IPTG (Sigma) at $37^{\circ} \mathrm{C}$ for $6 \mathrm{~h}$. The cells were harvested by centrifugation, and the pellet was re-suspended completely by mixing in phosphate-buffered saline (PBS). Following ultrasonication, recombinant mTLNE was purified through a Ni-NTA agarose (KWBIO, China) according to manufacturer's instructions, and the concentration of was determined by a bicinchoninic acid Protein Assay Kit (Pierce).

\section{SDS-PAGE and Western blotting assay}

All samples were mixed with loading buffer and loaded onto a homogeneous $12 \%$ polyacrylamide gel. Western blotting analysis was performed using the corresponding antibodies described as above. In brief, the PVDF membranes were incubated with the corresponding antibody at room temperature for $1 \mathrm{~h}$, followed by blocking in 10\% skim milk overnight at $4^{\circ} \mathrm{C}$. A horse-radish-peroxidase (HRP)-conjugated secondary antibody at a dilution of 1:5000 was used to detect the primary antibody. The membranes were subjected to three washes for $10 \mathrm{~min}$ each time in PBS containing 0.05\% Tween 20 and developed with ECL Western substrate (Bio-Rad).

\section{Enzyme-linked immunosorbent assay (ELISA)}

The 96-well microtiter plates were coated with coating buffer ( $\mathrm{pH}$ 9.6) containing $1 \mu \mathrm{g} / \mathrm{ml}$ of mTLNE overnight at $4^{\circ} \mathrm{C}$ followed by $10 \%$ skim milk blocking. The coated plate was then incubated with rabbit (1:400) or mouse (1:500) anti-EV71 antibody at $37^{\circ} \mathrm{C}$ for $1 \mathrm{~h}$, and followed by incubating HRP-conjugated secondary antibodies at $37^{\circ} \mathrm{C}$ for $30 \mathrm{~min}$. A total of $100 \mu \mathrm{l}$ of TMB peroxidase substrate was added for incubation for $15 \mathrm{~min}$ at room temperature. Finally, the absorbance at $450 \mathrm{~nm}$ was recorded using an ELISA plate reader.

\section{Mice immunization}

All animal experimental procedures were carried out in strict accordance with and approved by the Animal Experiment Committee of Beijing Institute of Microbiology and Epidemiology. Groups of 6-week-old female BALB/c mice $(\mathrm{n}=10)$ were inoculated with $50 \mu \mathrm{g}$ of mTLNE protein, or Trx protein (control group) by intraperitoneal (i.p.) injection with Freund's complete adjuvant (Sigma). All mice were then boosted twice with the same dose in Freund's incomplete adjuvant (Sigma) at a 2-week interval. Two weeks after each immunization, serum samples were prepared and stored frozen until use.

\section{Antibody response assay}

The titers of IgG antibody in mice sera were detected by IFA as previously described [52]. In brief, confluent RD cells infected with EV71 were harvested and suspended in DMEM containing 10\% FBS. The suspended cells were then inoculated onto slides and fixed with acetone for $30 \mathrm{~min}$ in $-20^{\circ} \mathrm{C}$. All serum samples were serially diluted (two fold) in PBS, and mice polyclonal antibodies (1:100 dilution) against EV71 were used as positive control. After incubation for $1 \mathrm{~h}$ at $37^{\circ} \mathrm{C}$, the slides were washed three times in PBS. Then, Alexa Fluor ${ }^{\circ} 488$ 
conjugated goat anti-mouse IgG (Invitrogen) in 0.02\% Evans blue was added and incubated for $30 \mathrm{~min}$ at $37^{\circ} \mathrm{C}$. Finally, positive cells were detected using a fluorescent microscope (Olympus). The IgG subtype profiles in mouse sera were determined with a commercially available mouse immunoglobulin isotyping kit (Invitrogen) according to the manufacturer's instruction.

The IgG titers of the immunized serum to each epitope (VP1-SP55, VP1-SP70 and VP2-SP28) were determined by ELISA. The unconjugated synthetic peptides representing the amino acid sequence of VP1-SP55, VP1-SP70 or VP2-SP28 were synthesized by Shanghai Bootech Bioscience\&Technology Co., Ltd (Shanghai, China). The 96-well microtiter plates were coated with $100 \mu \mathrm{l}$ of coating buffer containing $15 \mu \mathrm{g} / \mathrm{ml}$ of unconjugated synthetic peptides. All sera samples serially diluted (two fold) in PBS were incubated in triplicate wells $(100 \mu \mathrm{l} /$ well $)$ for $1 \mathrm{~h}$ at $37^{\circ} \mathrm{C}$. Following procedures were made as described in Methods "ELISA". IgG antibody titers were expressed by the highest serum dilution at which the absorbance at $450 \mathrm{~nm}$ is higher than cut off value.

The neutralizing antibody titers against different genotype of EV71 were measured by microneutralization assay in Vero cells as previously described [53]. The neutralizing antibody titer was calculated using the ReedMuench method [51].

\section{Cytokine analysis}

The production of cytokine from stimulated splenocytes was detected by enzyme-linked immunospot (ELISPOT) analysis using $\mathrm{BD}^{\mathrm{TM}}$ ELISPOT Set. In brief, the 96-well plates was coated respectively with IFN- $\gamma$, IL-2, IL-4, IL-6 capture antibody overnight at $4^{\circ} \mathrm{C}$. Spleen cells $\left(10^{6} /\right.$ well) from the immunized mice were added and cultured at $37^{\circ} \mathrm{C}$ for $36 \mathrm{~h}$, with total proteins of heat-inactivated EV71 (100 PFU/well) or ConA (250 ng/well, Sigma). Following procedures were made according to the manufacturer's instruction.

\section{In vivo challenge experiments}

The neonatal mice model of EV71 infection has been described [37]. Groups of BALB/c neonatal mice $(n \geq 5)$ were intracranially (i.c.) inoculated with $10 \mathrm{LD}_{50}$ of EV71 strain AH08/06, and $40 \mu \mathrm{l}$ of anti-mTLNE or anti-Trx serum was i.p. administered at $4 \mathrm{~h}$ post infection. PBS was set as negative control. The mortality was then monitored for at least 21 days.

\section{Statistical analysis}

The survival curve of each group was compared by using the Log-rank test with GraphPad Prism 5.0, and the other data were analyzed using $t$-test, and $p<0.05$ was considerate as significance.

\section{Competing interests}

The authors declare that they have no competing interests.

\section{Authors' contributions}

Conceived and designed the experiments: YXL HZ CFQ. Performed the experiments: YXL HZ SYZ. Analyzed the data: YXL HZ RYC YQD JFH CFQ. Contributed reagents/materials/analysis tools: JM LL SYZ EDQ. Wrote the paper: YXL HZ CFQ. All authors read and approved the final manuscript.

\section{Acknowledgments}

All the experiments were performed in Dr. Cheng-Feng Qin's lab. This work was supported by the National Natural Science Foundation of China (No. 81000721 and No. 31270195) and the Beijing Natural Science Foundation (No. 7112108 and No. 7122129). C.F. Qin was supported by the Beijing Nova Program of Science and Technology (No. 2010B041).

Received: 16 January 2014 Accepted: 30 April 2014

Published: 6 May 2014

\section{References}

1. Bible JM, Pantelidis P, Chan PK, Tong CY: Genetic evolution of enterovirus 71: epidemiological and pathological implications. Rev Med Virol 2007, 17:371-379

2. Cardosa MJ, Krishnan S, Tio PH, Perera D, Wong SC: Isolation of subgenus B adenovirus during a fatal outbreak of enterovirus 71-associated hand, foot, and mouth disease in Sibu, Sarawak. Lancet 1999, 354:987-991.

3. Chan KP, Goh KT, Chong CY, Teo ES, Lau G, Ling AE: Epidemic hand, foot and mouth disease caused by human enterovirus 71 , Singapore. Emerg Infect Dis 2003, 9:78-85.

4. Ho M, Chen ER, Hsu KH, Twu SJ, Chen KT, Tsai SF, Wang JR, Shih SR: An epidemic of enterovirus 71 infection in Taiwan: Taiwan enterovirus epidemic working group. N Engl J Med 1999, 341:929-935.

5. Mao LX, Wu B, Bao WX, Han FA, Xu L, Ge QJ, Yang J, Yuan ZH, Miao CH, Huang XX, Zhang C, Xu H: Epidemiology of hand, foot, and mouth disease and genotype characterization of enterovirus 71 in Jiangsu, China. J Clin Virol 2010, 49:100-104

6. Wu Y, Yeo A, Phoon MC, Tan EL, Poh CL, Quak SH, Chow VT: The largest outbreak of hand; foot and mouth disease in Singapore in 2008: the role of enterovirus 71 and coxsackievirus A strains. Int J Infect Dis 2010, 14:e1076-e1081.

7. Hosoya M, Kawasaki Y, Sato M, Honzumi K, Kato A, Hiroshima T, Ishiko H, Suzuki H: Genetic diversity of enterovirus 71 associated with hand, foot and mouth disease epidemics in Japan from 1983 to 2003. Pediatr Infect Dis J 2006, 25:691-694

8. Mizuta K, Abiko C, Murata T, Matsuzaki Y, Itagaki T, Sanjoh K, Sakamoto M, Hongo S, Murayama S, Hayasaka K: Frequent importation of enterovirus 71 from surrounding countries into the local community of Yamagata, Japan, between 1998 and 2003. J Clin Microbiol 2005, 43:6171-6175.

9. Herrero LJ, Lee CS, Hurrelbrink RJ, Chua BH, Chua KB, McMinn PC: Molecular epidemiology of enterovirus 71 in peninsular Malaysia, 1997-2000. Arch Virol 2003, 148:1369-1385.

10. Chang LY: Enterovirus 71 in Taiwan. Pediatr Neonatol 2008, 49:103-112.

11. Wu CN, Lin YC, Fann C, Liao NS, Shih SR, Ho MS: Protection against lethal enterovirus 71 infection in newborn mice by passive immunization with subunit VP1 vaccines and inactivated virus. Vaccine 2001, 20:895-904.

12. Chen HF, Chang MH, Chiang BL, Jeng ST: Oral immunization of mice using transgenic tomato fruit expressing VP1 protein from enterovirus 71 Vaccine 2006, 24:2944-2951.

13. Chiu $\mathrm{CH}_{\text {, }} \mathrm{Chu} \mathrm{C}$, He CC, Lin TY: Protection of neonatal mice from lethal enterovirus 71 infection by maternal immunization with attenuated salmonella enterica serovar Typhimurium expressing VP1 of enterovirus 71. Microbes Infect 2006, 8:1671-1678.

14. Arita M, Nagata N, Iwata N, Ami Y, Suzaki Y, Mizuta K, Iwasaki T, Sata T, Wakita T, Shimizu $\mathrm{H}$ : An attenuated strain of enterovirus 71 belonging to genotype a showed a broad spectrum of antigenicity with attenuated neurovirulence in cynomolgus monkeys. J Virol 2007, 81:9386-9395.

15. Liu CC, Lian WC, Butler M, Wu SC: High immunogenic enterovirus 71 strain and its production using serum-free microcarrier vero cell culture. Vaccine 2007, 25:19-24

16. Tung WS, Bakar SA, Sekawi Z, Rosli R: DNA vaccine constructs against enterovirus 71 elicit immune response in mice. Genet Vaccines Ther 2007, 5:6. 
17. Chung YC, Ho MS, Wu JC, Chen WJ, Huang JH, Chou ST, Hu YC: Immunization with virus-like particles of enterovirus 71 elicits potent immune responses and protects mice against lethal challenge. Vaccine 2008, 26:1855-1862.

18. Ong KC, Devi S, Cardosa MJ, Wong KT: Formaldehyde-inactivated whole-virus vaccine protects a murine model of enterovirus 71 encephalomyelitis against disease. J Virol 2010, 84:661-665.

19. Cheng A, Fung CP, Liu CC, Lin YT, Tsai HY, Chang SC, Chou AH, Chang JY, Jiang RH, Hsieh YC, Su IJ, Chong PC, Hsieh SM: A Phase I, randomized, open-label study to evaluate the safety and immunogenicity of an enterovirus 71 vaccine. Vaccine 2013, 31:2471-2476.

20. Liang ZL, Mao QY, Wang YP, Zhu FC, Li JX, Yao X, Gao F, Wu X, Xu M, Wang JZ: Progress on the research and development of inactivated EV71 whole-virus vaccines. Hum Vaccin Immunother 2013, 9(8):1701-1705.

21. Zhu FC, Meng FY, Li JX, Li XL, Mao QY, Tao H, Zhang YT, Yao X, Chu K, Chen $\mathrm{QH}, \mathrm{Hu}$ YM, Wu X, Liu P, Zhu LY, Gao F, Jin H, Chen YJ, Dong YY, Liang YC, Shi NM, Ge HM, Liu L, Chen SG, Ai X, Zhang ZY, Ji YG, Luo FJ, Chen XQ, Zhang $Y$, Zhu LW: Efficacy, safety, and immunology of an inactivated alum-adjuvant enterovirus 71 vaccine in children in China: a multicentre, randomised, double-blind, placebo-controlled, phase 3 trial. Lancet 2013, 381:2024-2032.

22. Chan YF, Sam IC, AbuBakar S: Phylogenetic designation of enterovirus 71 genotypes and subgenotypes using complete genome sequences. Infect Genet Evol 2010, 10:404-412.

23. Xu J, Qian Y, Wang S, Serrano JM, Li W, Huang Z, Lu S: EV71: an emerging infectious disease vaccine target in the ear East? Vaccine 2010, 28:3516-3521.

24. Foo DG, Alonso S, Chow VT, Poh CL: Passive protection against lethal enterovirus 71 infection in newborn mice by neutralizing antibodies elicited by a synthetic peptide. Microbes Infect 2007, 9:1299-1306.

25. Li X, Mao C, Ma S, Wang X, Sun Z, Yi Y, Guo M, Shen X, Sun L, Bi S: Generation of neutralizing monoclonal antibodies against enterovirus 71 using synthetic peptides. Biochem Biophys Res Commun 2009, 390:1126-1128.

26. Lim XF, Jia Q, Khong WX, Yan B, Premanand B, Alonso S, Chow VT, Kwang J: Characterization of an isotype-dependent monoclonal antibody against linear neutralizing epitope effective for prophylaxis of enterovirus 71 infection. PloS One 2012, 7:e29751.

27. Liu CC, Chou AH, Lien SP, Lin HY, Liu SJ, Chang JY, Guo MS, Chow YH, Yang WS, Chang KH, Sia C, Chong P: Identification and characterization of a cross-neutralization epitope of enterovirus 71. Vaccine 2011, 29:4362-4372.

28. Dudek NL, Perlmutter P, Aguilar MI, Croft NP, Purcell AW: Epitope discovery and their use in peptide based vaccines. Curr Pharm Des 2010, 16:3149-3157.

29. Sette A, Fikes J: Epitope-based vaccines: an update on epitope identification, vaccine design and delivery. Curr Opin Immunol 2003, 15:461-470.

30. Dong XN, Chen Y, Wu Y, Chen YH: Candidate multi-peptide-vaccine against classical swine fever virus induced potent immunity with serological marker. Vaccine 2005, 23:3630-3633.

31. Ichihashi T, Yoshida R, Sugimoto C, Takada A, Kajino K: Cross-protective peptide vaccine against influenza $A$ viruses developed in HLA-A*2402 human immunity model. PLOS One 2011, 6:e24626.

32. Koopman G, Beenhakker N, Nieuwenhuis I, Doxiadis G, Mooij P, Drijfhout JW, Koestler J, Hanke T, Fagrouch Z, Verschoor EJ, Bontrop RE, Wagner R, Bogers WM, Melief CJ: DNA/long peptide vaccination against conserved regions of SIV induces partial protection against SIVmac251 challenge. AIDS 2013, 27:2842-2851.

33. Purcell AW, McCluskey J, Rossjohn J: More than one reason to rethink the use of peptides in vaccine design. Nat Rev Drug Discov 2007, 6:404-414.

34. El-Awady MK, El Gendy M, Waked I, Tabll AA, El Abd Y, Bader El D, El Shenawy R, Allam A, Abdelhafez TH, Dawood RM: Immunogenicity and safety of HCV E1E2 peptide vaccine in chronically HCV-infected patients who did not respond to interferon based therapy. Vaccine 2013. doi: http://dx.doi.org/10.1016/j.vaccine.2013.07.074.

35. Liu JN, Wang W, Duo JY, Hao Y, Ma CM, Li WB, Lin SZ, Gao XZ, Liu XL, XU YF, Xu WB, Qin C, Zhang LF: Combined peptides of human enterovirus 71 protect against virus infection in mice. Vaccine 2010, 28:7444-7451.

36. Tian X, Su X, Li X, Li H, Li T, Zhou Z, Zhong T, Zhou R: Protection against enterovirus 71 with neutralizing epitope incorporation within adenovirus type 3 hexon. PLoS One 2012, 7:e41381.

37. Lin YC, Wu CN, Shih SR, Ho MS: Characterization of a vero cell-adapted virulent strain of enterovirus 71 suitable for use as a vaccine candidate. Vaccine 2002, 20:2485-2493.
38. Sette A, Keogh E, Ishioka G, Sidney J, Tangri S, Livingston B, Mckinney D, Newman M, Chesnut R, Fikes J: Epitope identification and vaccine design for cancer immunotherapy. Curr Opin Investig Drugs 2002, 3:132-139.

39. Sette A, Newman M, Livingston B, McKinney D, Sidney J, Ishioka G, Tangri S, Alexander J, Fikes J, Chesnut R: Optimizing vaccine design for cellular processing, MHC binding and TCR recognition. Tissue Antigens 2002, 59:443-451.

40. Livingston BD, Newman M, Crimi C, McKinney D, Chesnut R, Sette A: Optimization of epitope processing enhances immunogenicity of multiepitope DNA vaccines. Vaccine 2001, 19:4652-4660.

41. Li HY, Han JF, Qin CF, Chen R: Virus-like particles for enterovirus 71 produced from saccharomyces cerevisiae potently elicits protective immune responses in mice. Vaccine 2013, 31:3281-3287.

42. Foo DG, Alonso S, Phoon MC, Ramachandran NP, Chow VT, Poh CL: Identification of neutralizing linear epitopes from the VP1 capsid protein of enterovirus 71 using synthetic peptides. Virus Res 2007, 125:61-68.

43. Wang SM, Chen IC, Su LY, Huang KJ, Lei HY, Liu CC: Enterovirus 71 infection of monocytes with antibody-dependent enhancement. Clin Vaccine Immunol 2010, 17:1517-1523.

44. Han JF, Cao RY, Deng YQ, Tian X, Jiang T, Qin ED, Qin CF: Antibody dependent enhancement infection of enterovirus 71 in vitro and in vivo. Virol J 2011, 8:106.

45. Chen IC, Wang SM, Yu CK, Liu CC: Subneutralizing antibodies to enterovirus 71 induce antibody-dependent enhancement of infection in newborn mice. Med Microbiol Immunol 2013, 202:259-265.

46. Cao RY, Dong DY, Liu RJ, Han JF, Wang GC, Zhao H, Li XF, Deng YQ, Zhu SY, Wang XY, Lin F, Zhang FJ, Chen W, Qin ED, Qin CF: Human IgG subclasses against enterovirus Type 71: neutralization versus antibody dependent enhancement of infection. PLoS One 2013, 8:e64024.

47. Foo DG, Macary PA, Alonso S, Poh CL: Identification of human CD4 T-cell epitopes on the VP1 capsid protein of enterovirus 71. Viral Immunol 2008, 21:215-224.

48. Cello J, Strannegard O, Svennerholm B: A study of the cellular immune response to enteroviruses in humans: identification of cross-reactive $T$ cell epitopes on the structural proteins of enteroviruses. J Gen Virol 1996, 77(Pt 9):2097-2108.

49. Zhao H, Li HY, Han JF, Deng YQ, Li YX, Zhu SY, He YL, Qin ED, Chen R, Qin CF: Virus-like particles produced in Saccharomyces cerevisiae elicit protective immunity against coxsackievirus A16 in mice. Appl Microbiol Biotechnol 2013, 97:10445-10452.

50. Han JF, Cao RY, Tian X, Yu M, Qin ED, Qin CF: Producing infectious enterovirus type 71 in a rapid strategy. Virol J 2010, 7:116.

51. REED LJ, MUENCH H: A simple method of estimating fifty per cent endpoints. Am J Epidemiol 1938, 27:493-497.

52. Chen S, Yu M, Jiang T, Deng Y, Qin C, Qin E: Induction of tetravalent protective immunity against four dengue serotypes by the tandem domain III of the envelope protein. DNA Cell Biol 2007, 26:361-367.

53. Cao RY, Han JF, Jiang T, Tian X, Yu M, Deng YQ, Qin ED, Qin CF: In vitro and in vivo characterization of a new enterovirus type 71-specific human intravenous immunoglobulin manufactured from selected plasma donors. J Clin Virol 2011, 51:246-249.

\section{doi:10.1186/1743-422X-11-79}

Cite this article as: Li et al.: Recombinant tandem multi-linear neutralizing epitopes of human enterovirus 71 elicited protective immunity in mice. Virology Journal 2014 11:79. 